\title{
Palavra de Ordem em Aula de Matemática: o erro e a besteira
}

\author{
Word of Order in Math Class: the error and mistake
}

Marta Elaine de Oliveira*

\begin{abstract}
Resumo
O presente texto propõe uma discussão acerca da noção de erro e de besteira enquanto palavra de ordem em aula de matemática. Traz um evento que se deu em sala de aula de formação de professores que ensinarão matemática nos anos iniciais do Ensino Fundamental, que problematiza uma linguagem que se faz a partir de um ponto de vista, o do professor. Nessa composição, encontros fecundos com Friedrich Nietzsche e Gilles Deleuze permitem pensar acerca da aprendizagem às condições da invenção em sala de aula. Um deslocamento no modo de reprodução de um modelo que se coloca como caminho que leva ao resultado correto e a um pensamento adequado, traz a invenção de um modo de operar que inquieta um pensamento e que rompe com um modo já normatizado. Um erro e uma besteira são tomados como aprendizagem inventiva junto a um modo de pensar o aprender.
\end{abstract}

Palavras-chave: Aprendizagem. Erro. Besteira. Formação. Matemática.

\begin{abstract}
This paper proposes a discussion about the notion of error and mistake as word of order in a math class. It brings an event that occurred in a teacher's training classroom in the early years of elementary school, which discusses the language from the teacher's point of view. In this composition, we used authors such as Friedrich Nietzsche and Gilles Deleuze, which allowed us to think about the invention conditions for learning in the classroom. A displacement in the playback mode of a model that arises as a path leading to the correct result and adequate thought, brings the invention of an operating way that troubles a thought and breaks an already regulated way. The error and mistake are taken as inventive learning along a way of learning thinking.
\end{abstract}

Keywords: Learning. Error. Mistake. Education. Mathematics.

\section{0 ponto de vista é a vista de um ponto? Um erro? Uma besteira?}

Fixo instantes súbitos que trazem em si a própria morte e outros nascem - fixos instantes de metamorfose e é de terrível beleza a sua sequência e concomitância. (LISPECTOR, 1998).

Em uma aula de ensino de matemática, para estudantes do curso de Pedagogia, um grupo apresenta uma oficina ${ }^{1}$. Distribuem cinco tampinhas, de cores variadas, a cada aluna. Em seguida, solicitam que observem as cores, que identifiquem se são diferentes ou iguais.

\footnotetext{
* Doutoranda no Curso de Pós-Graduação em Educação pela Universidade Federal de Juiz de Fora (UFJF), Juiz de Fora, Minas Gerais, Brasil. Endereço para correspondência: Rua José Lourenço Kelmer, s/n, Campus Universitário, Bairro São Pedro, CEP: 36036-900, Juiz de Fora, Minas Gerais, Brasil. E-mail: martaoliveirajf@gmail.com.
} 
Posteriormente, os integrantes dos grupos recolhem as tampinhas. Selecionam as tampinhas de mesma cor e colocam-nas ao chão, formando agrupamentos de cinco tampinhas em cada fileira. Fazem isso com todas as cores (Figura 1).

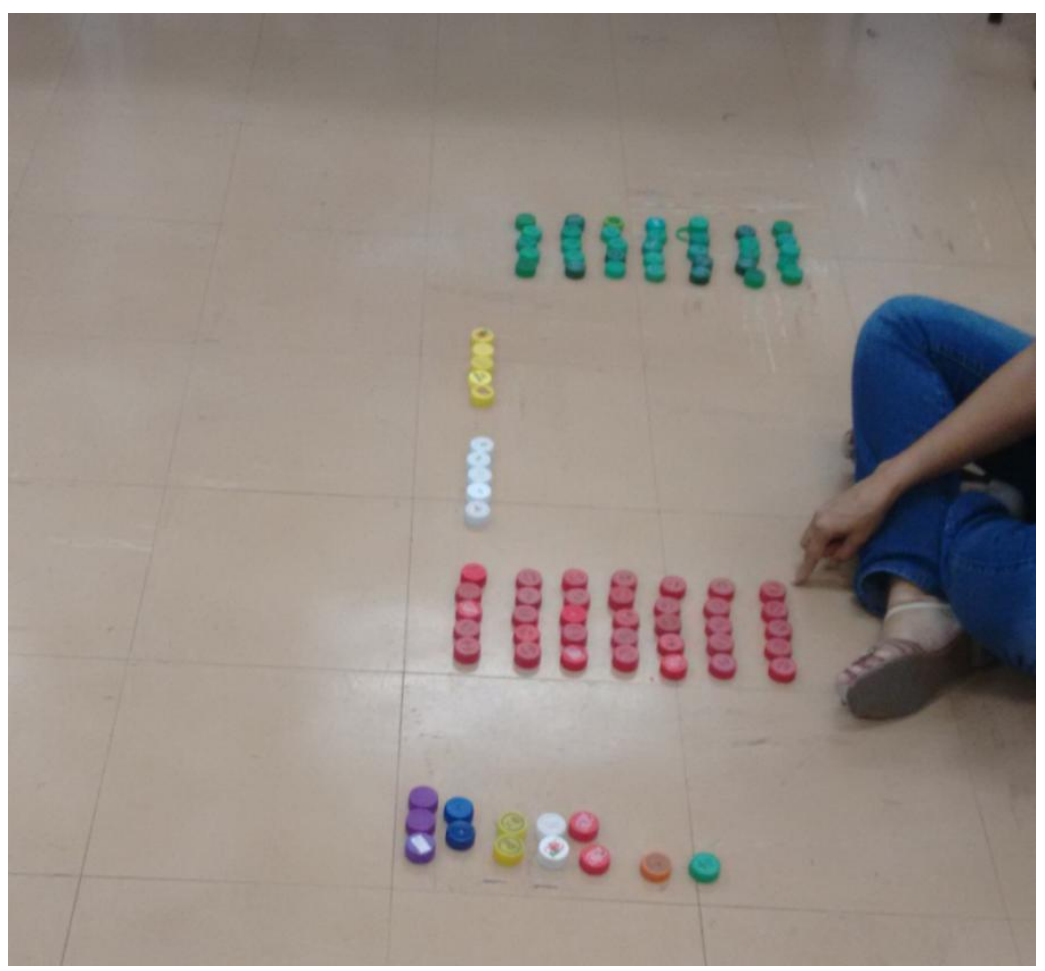

Figura 1 - Atividade em sala de aula / Disposição das tampinhas ao chão pelo grupo proponente da oficina. De cima para baixo, grupo de tampinhas verdes, amarelas, brancas, vermelhas e cores variadas.

Fonte: arquivo da pesquisadora.

Depois de dispor todas as tampinhas em grupos separados por cores, e de ter enfileirado de cinco em cinco as tampinhas de mesma cor, deixando ao lado as tampinhas que não foram agrupadas, várias perguntas são feitas aos alunos.

- Quantas fileiras foram formadas com as tampinhas vermelhas?

Uma aluna responde:

- Cinco fileiras.

- Não são cinco fileiras, são sete - diz a integrante do grupo que organizava as tampinhas no chão. E continua:

- Você está vendo errado, venha daqui onde estou para você ver que são sete fileiras com cinco tampinhas.

Grupo propositor e os alunos dão-se por satisfeitos e dão continuidade às arguições.

- Por que existem tampinhas que não foram agrupadas? - a propositora pergunta.

Um silêncio aparente é interrompido por uma voz que diz:

\footnotetext{
${ }^{1}$ A atividade descrita foi desenvolvida em sala de aula da disciplina de Ensino de Matemática, em 2016, pelos graduandos do curso de Pedagogia, de uma faculdade particular de Juiz de Fora e faz parte, também, do registro no diário de banalidades produzido no processo de doutoramento da autora.
} 
- Porque não tem tampinhas de mesma cor para formar grupos.

O grupo insiste:

- Mas quantas tampinhas da mesma cor seriam necessárias para serem agrupadas?

Alguém responde:

- Mais quantas cores quiserem.

Um pouco nervosa e contrariada, a propositora da atividade diz:

- A cor não é importante nesse caso, o que importa é a quantidade delas. Então eu repito: por que existem tampinhas que não foram agrupadas?

Alunas dizem não entender a atividade.

Uma aula de ensino de matemática problematiza seu ensino, problematiza o ponto de vista do professor e lugar dessa hegemonia. Implica-se com os modos de ensinar e aprender.

Em qual ponto de vista um erro se faz? A graduanda errou ao ver cinco fileiras ao invés de sete?

Não há ponto de vista que observa a cor em matemática? Responder em cor é besteira?

A quantidade em matemática é o que prevalece? A cor não importa nesse caso? A cor importa em matemática? A cor é uma besteira?

Corrigir o erro? Resistir à besteira? Qual ponto de vista que faz corrigir o erro e resistir à besteira?

Sob esse ponto de vista, o erro e a besteira são distorções ao pensamento. O erro e a besteira pensados como distorções evidenciam um pensamento desejável, pautado na crença de que o pensar é uma faculdade natural do sujeito. Entende-se que o pensar possa ser ensinado e aprendido, focando o processo de ensinar e aprender a pensar bem. Como se ensinar fosse um caminho prescritivo para se chegar ao aprender.

O erro deve ser corrigido e eliminado: venha daqui onde estou para você ver que são sete fileiras com cinco tampinhas. Já a besteira deve ser ignorada: Então, repito: por que existem tampinhas que não foram agrupadas?

Em um ensino o ponto de vista a ser considerado é o do professor? É ele quem diz, com suas palavras de ordem, a vista do ensino, do modo correto de ver e de selecionar critérios e atributos relevantes ao ensino?

Espera-se respostas sob um ponto de vista. Determinado modo de olhar é um erro.

Espera-se respostas a partir de uma categoria de análise. Quantidade nada tem a ver com cores. 
Nesse ponto de vista, se há erros, esses são produzidas pelo modo de olhar para o objeto. Se há besteiras, essas são produzidas por um sujeito que não se adequa ao pensamento vigente.

Uma neurotização em sala de aula requer uma produção de respostas condizentes ao que se espera. Não se espera besteiras. Categoriza-se o que vem a ser besteiras.

$\mathrm{Na}$ escola, sob determinado ponto de vista, a prevalência é da quantidade nos agrupamentos, espera-se que o aluno só se envolva com as quantidades. A resposta, em observância das cores, não é suficiente. Cor não é um atributo relevante nessa atividade.

Mas cor é um atributo relevante em matemática? Cor é um atributo relevante na escola?

Há cor na escola? Há cor na matemática? Há cor no ensino de matemática?

A cor é só um colorido, um olhar mais ameno, não é critério. Espera-se que se compreenda isso.

Quando se habita a esperança de compreensão, ninguém sai impune.

O diálogo é a conversa perfeita, porque tudo o que uma pessoa diz recebe sua cor definida, seu tom, seu gesto de acompanhamento, em estrita referência àquele com quem fala, ou seja, tal como sucede na troca epistolar, em que a mesma pessoa tem dez maneiras de exprimir sua alma, conforme escreva a este ou àquele indivíduo. No diálogo há uma única refração do pensamento: ela é produzida pelo interlocutor, como o espelho no qual desejamos ver nossos pensamentos refletidos do modo mais belo possível. Mas como se dá com dois, três ou mais interlocutores? Então a conversa perde necessariamente em finura individualizadora, as várias referências se cruzam e se anulam; a locução que agrada a um não satisfaz a índole de outro. Por isso o indivíduo é forçado, lidando com muitos, a se recolher em si mesmo, a apresentar os fatos como são, mas tira dos assuntos o lúdico ar de humanidade que faz da conversa uma das coisas mais agradáveis do mundo (NIETZSCHE, 2015, p. 196).

\section{Palavra de Ordem: um erro, uma besteira} Estou atrás do que fica do pensamento.
Inútil querer me classificar: eu simplesmente escapulo
não deixando, gênero não me pega mais.

(LISPECTOR, 1998).

Em um ensino há muitas palavras e poucos movimentos. Muitas palavras que não falam dos muitos movimentos que são negados. Ou será que há palavras que calam o movimento, que lá há? Isso é besteira!

Em um ensino: por pura finalidade, as palavras se tornam obrigação, se tornam palavras de ordem, incorporação de um meio a um determinado fim. Um erro!

Palavra de ordem: Erro. Besteira.

Uma linguagem se faz em aula de matemática com suas palavras de ordem. 
A professora não se questiona quando interroga um aluno, assim como não se questiona quando ensina uma regra de gramática ou de cálculo. Ela não "ensigna", dá ordens, comanda. Os mandamentos do professor não são exteriores nem se acrescentam ao que ele nos ensina. Não provêm de significações primeiras, não são as consequências de informações: a ordem se apoia sempre, e desde o início, em ordens, por isso é redundância. A máquina do ensino obrigatório não comunica informações, mas impõe à criança coordenadas semióticas com todas as bases duais da gramática (masculino-feminino, singular-plural, substantivo-verbo, sujeito do enunciado-sujeito de enunciação etc.). Mais do que o senso comum, faculdade que centralizaria as informações, é preciso definir uma faculdade abominável que consiste em emitir, receber e transmitir palavras de ordem. A linguagem não é mesmo feita para que se acredite nela, mas para obedecer e fazer obedecer (DELEUZE; GUATARRI, 2011, p. 11-12).

A linguagem "serve para mandar e fazer obedecer, assim como para desempenhar a própria obediência. A linguagem é sempre uma espécie de 'palavra de ordem', que implica em uma relação de mando-obediência" (GALLO; SOUZA, 2007, p. 125).

Uma linguagem diz do modo de se consertar o erro. Uma linguagem exclui os que dizem besteiras.

É difícil determinar a extensão da palavra de ordem.

Não se trata de uma origem da linguagem, já que a palavra de ordem é apenas uma função-linguagem, uma função coextensiva à linguagem [...] é porque a linguagem não é estabelecida entre algo visto (ou sentido) e algo dito, mas vai sempre de um dizer a um dizer (DELEUZE; GUATTARI, 2011, p. 13).

Em um quarto escuro, filho e pai conversam. O filho segura em suas mãos uma carta que revelaria ao amigo seu noivado, deseja aconselhamento de seu pai sobre essa revelação ${ }^{2}$.

Em quarto escuro, o pai e filho discutem, pai entra no processo de acusação ao filho.

Filho sente-se culpado.

Tenta colocar o pai em local mais arejado. Trazê-lo à luz.

O pai condena o filho: "No fundo tu foste apenas uma criança inocente, mas mais no fundo ainda foste um homem diabólico! E por isso fique sabendo: eu te condeno à morte por afogamento!"' (KAFKA, 2014, p. 126).

Por palavra de ordem Deleuze e Guattari (2011, p. 16) compreendem:

\footnotetext{
${ }^{2}$ Há, aqui, uma referência à obra "O Veredicto", do autor Franz Kafka (2014). A narrativa tem por personagem principal George. Ele escreve a um amigo, o qual não revela o nome, e que mudou-se para Petersburgo. George, em uma luta a respeito da indecisão de relatar ou não ao amigo sobre seu noivado em uma carta, pede aconselhamento do Pai. Com a carta na mão, George vai ao quarto do pai e lhe diz que vai anunciar o noivado ao amigo. Em um quarto escuro, o pai, já envelhecido e acamado, desacredita o filho por suas mentiras, acusando-o de não ter nenhum amigo em outra cidade. $\mathrm{O}$ pai admite a existência do amigo, e afirma que o filho traiu a amizade do amigo, a memória da mãe falecida, ao iniciar um relacionamento com uma mulher. Após a discussão, o pai ordena ao filho que morra por afogamento.
} 
[...] a relação de qualquer palavra ou de qualquer enunciado com pressupostos implícitos, ou seja, com atos de fala que se realizam no enunciado, e que podem se realizar apenas nele. As palavras de ordem não remetem, então, somente aos comandos, mas a todos os atos que estão ligados aos enunciados por uma "obrigação social". Não existe enunciado que não apresente esse vínculo, direta ou indiretamente. Uma pergunta, uma promessa, são palavras de ordem. A linguagem só pode ser definida pelo conjunto das palavras de ordem, pressupostos implícitos ou atos de fala que percorrem uma língua em um dado momento.

"Em toda palavra de ordem, mesmo de um pai a seu filho, há uma pequena sentença de morte - um Veredito, dizia Kafka” (DELEUZE; GUATTARI, 2011, p. 13).

O que fazer, então, com um veredito? Erro, que erro? Besteira, que Besteira?

Corpo aluno, corpo professor, corpo escola, corpo família, agenciamentos, corpo ensino, corpo matemática, corpo palavra. Uma mistura dos efeitos desses corpos produz um sentido. Que ordem é esse sentido? A ordem de um acontecimento? O que se passa depois? São ações-paixões afetando os corpos (corpo do errante, corpo do bestial, corpo escola).

Crime - a acusação de não ter visto pelo ponto de vista do professor e, além disso, produzir bobagens, pensamentos inadequados. Crime duplamente qualificado

A sentença - um parecer, a partir do ponto de vista do professor, produzir um olhar correto, obedecer a caminhos predeterminados e uma linguagem que se encaixe, que se adeque ao já pensado.

Do crime à sentença, transforma o corpo aluno errado ao correto, transforma a besteira em um pensar adequado. O corpo bestial em um corpo adequado.

Da reparação do erro: produções de caminhos metodológicos que visam colocar na linha o corpo aluno que erra.

Da reparação da besteira: uma tomada de consciência do pensar inadequado.

Corpo errante e bestial, "a transformação incorpórea é reconhecida por sua instantaneidade, por sua imediatidade, pela simultaneidade do enunciado que a exprime e do efeito que ela produz" (DELEUZE; GUATTARI, 2011, p. 20).

O erro pensado, em uma imagem dogmática do pensamento é como uma "desventura do pensamento" (DELEUZE, 2006, p. 146). O erro "é apenas o reverso de uma ortodoxia racional e ainda testemunha em favor daquilo de que ele se desvia, em favor de uma retidão, de uma boa natureza e de uma boa vontade daquele que é dito enganar-se" (DELEUZE, 2006, p. 147).

O erro rende-se à homogeneidade da verdade, está a serviço de uma transcendência. A evidenciação do erro busca atender a uma idealização. 
Nesse sentido, o erro já faz parte do território daquilo que se é coerente pensar, e é “apresentado como único 'negativo' do pensamento” (DELEUZE, 2006, p. 214).

Produzir uma desterritorialização da noção de erro e suspeitar dos caminhos de correção para uma possível descoberta do verdadeiro pode estar em consonância com o que Clareto e Silva (no prelo) investiram como possibilidade de se relacionar o erro, "como um desvio"3 do pensamento "um escape à reprodução de um modelo que se coloca como caminho que leva ao resultado correto. Invenção de um modo de operar que inquieta um pensamento, engendrando um pensar que rompe com um modo já normatizado, inaugurando um desvio como produção" (CLARETO; SILVA, no prelo).

As autoras desconfiam dos métodos que visam garantir um caminho para fazer do erro um retorno ao eixo desviado. Expressam que o erro, na perspectiva da análise do erro, “acontece mediante uma expectativa dada pelo conteúdo matemático disciplinar escolarizado, organizado para aquela série ou ano na qual o aluno se situa. Erro como um não cumprimento de uma expectativa de ensino pelo professor" (CLARETO; SILVA, no prelo).

O erro, então, nessa configuração apresenta-se como uma dissintonia entre o ensinar do professor e o aprender do aluno.

A possibilidade de pensar o erro como um desvio, e não como uma indissociabilidade do ensinar e aprender, pode produzir um pensar a situação de sala de aula que se envolve com os sentidos expressos no próprio pensamento, com uma criação. "Pensar é criar, não há outra criação, mas criar é, antes de tudo, engendrar 'pensar' no pensamento" (DELEUZE, 2006, p. 213).

$$
* * *
$$

$\mathrm{Na}$ imagem dogmática do pensamento, a besteira não é redutível ao erro. O conceito do erro não daria conta da besteira. A besteira é uma distorção ou inadequação do pensamento no qual se propunha a idealização.

Em artifícios de exclusão da besteira, um ensino crê na possibilidade de ensinar a pensar adequadamente. A noção de que existe um caminho para se pensar corretamente está associada à ideia do senso comum de pensamento, que se configura do seguinte modo: primeiro, existe um pensar que é um exercício natural; segundo, existe um sujeito que estabelece a boa vontade de conhecer o verdadeiro, porém, esse sujeito pode ser desviado da

\footnotetext{
${ }^{3}$ As autoras apropriam-se do sentido de desvio produzido por Deleuze e trazido por Guarienti (2012, p. 205) "O desvio é do plano do sensível, da intensidade, dos gestos micro e dos mínimos detalhes. [...] O desvio é aquilo que pode resistir ao campo dos saberes, campo do institucional, campo do molar. O desvio é molecular, é átomo, é fluxão [...]".
} 
verdade pelas paixões, pelo corpo, pelo sentido; e, por último, bastaria um método para se pensar corretamente.

Nesse sentido, estabelecem-se métodos para se atingir um pensamento desejável, pautado na crença de que o pensar é uma faculdade natural do sujeito. Entende-se que o pensar possa ser ensinado e aprendido, focando o processo de ensinar e aprender a pensar bem.

A matriz desse pensamento não aceita desvios no pensamento, pensamento puro, não aceita a besteira. Somente através das abstrações, submete o mundo do sensível para torná-lo inteligível.

A besteira não é a animalidade. $\mathrm{O}$ animal está garantido por formas específicas que o impedem de ser "besta". Foram frequentemente estabelecidas correspondências formais entre o rosto humano e as caras animais, isto é, entre diferenças individuais do homem e diferenças específicas do animal. Mas, assim procedendo, não se dá conta da besteira como bestialidade propriamente humana (DELEUZE, 2006, p. 148).

É preciso que o homem se dê conta de sua bestialidade. Só um homem produz para o outro o que é e o que não é besteira. Uma racionalidade traz esse imperativo.

A besteira, no mais das vezes nos processos educativos, é tratada por meio de medidas moralizantes relativas à fuga completa do tema trabalhado, um completo absurdo. Seria um pensamento que não se encaixa, que deve ser desconsiderado, que não se aproveita, o resto do pensamento. Um fluxo inconcebível por alguns professores.

Ao lidar com as sobras, com os restos, uma produção de rotas de fugas faz pensar na possibilidade de uma fluidez ao pensamento. Esse fluxo, produzido pelo que é descartado, pode se tornar potente como criação e como experimentação.

"A covardia, a crueldade, a baixeza, a besteira não são simplesmente potências do corpo ou fatos de caráter e de sociedade, mas estruturas do pensamento como tal" (DELEUZE, 2006, p. 218).

Como escapar desse pensamento representativo e garantir à diferença um lugar na diferença em si?

Nesse desvio, na fluidez da besteira, sem razão estabelecida e sem sentido predefinido, no despretensioso, no imprevisto, no desvalido, uma possibilidade de conectar o pensamento a algo nunca pensado. "É o fortuito ou a contingência do encontro que garante a necessidade daquilo que ela força a pensar" (DELEUZE, 2006, p. 211). Essa, talvez, seja a política e ética do pensamento que não se configura em modos de pensar condicionantes e condicionados, em categorias e em padrões estabelecidos de pensamento. 
A besteira não é o fundo, nem o individuo, mas a relação em que a individuação eleva o fundo sem poder dar-lhe forma (ele se eleva por meio do Eu, penetrando o mais profundamente na possibilidade do pensamento, constituindo o não reconhecido de toda recognição) (DELEUZE, 2006, p. 219).

\section{No processo de acusação pautado em uma transgressão, que aprendizagem acontece?}

Sim, quero a palavra última que também é tão primeira que já se confunde com a parte intangível do real. Ainda tenho medo de afastar da lógica porque caio no instintivo e no direto, e no futuro: a invenção do hoje é o meu único meio de instaurar o futuro. Desde já é futuro, e qualquer hora é hora marcada. Que mal porém tem eu me afastar da lógica? (LISPECTOR, 1998).

Do processo de acusação: um conserto. Eu te condeno a morrer afogado. Conhecimento morte.

Em um ensino de matemática. Acusações. Culpa. Um veredito: errado, besteira.

Um veredito se faz com suas palavras de ordem.

Que aprendizagem produz?

O quanto de morte há em uma aprendizagem? O que morre enquanto se aprende?

Morre-se um pouco a cada dia, em um enquadramento, em um ajuste nos encadeamentos, em um apaziguamento, em uma recriminação. Tudo para não permitir respirar.

O que o homem traz com suas promessas de moralidade do costume? Um torna-se homem confiável por sua uniformidade e constância. "uma orgulhosa consciência do que finalmente foi alcançado" (NIETZSCHE, 1998, p. 49).

Para esse homem: aprender é a manutenção de certas verdades: "algumas ideias devem tornar-se indeléveis, onipresentes, inesquecíveis, 'fixas', para que todo o sistema nervoso e intelectual seja hipnotizado por essas “ideias fixas"” (NIETZSCHE, 1998, p. 51).

Aprendizagem: incrustar, colar na alma uma significância, uma sentença de morte, através de suas palavras de ordem.

Um aprender suporta esse veredito? Como suportar modos outros de operar e pensar junto à matemática, para além desse veredito?

Quanto é possível suportar um veredito em aulas de matemática?

Como escapar?

Como habitar um outro território existencial nos limites da aprendizagem que procure, no sentido deleuziano, "trair-se as potências fixas que querem nos reter, as potências estabelecidas"? (DELEUZE, 1969/1998, p. 60). Em outras palavras, como bifurcar as noções de aprendizagem e de cognição para que seja possível produzir uma torção nesse modo de 
compreender e praticar a aprendizagem? É possível pensar a aprendizagem enquanto fomentadora de possibilidades de invenção, que por invenção entenda-se como superação de tendências recognitivas ${ }^{4}$ ?

Também, nesse sentido, na sala de aula de matemática, como fugir é criar vida, sair do eixo em um movimento de diferenciação em sala de aula de matemática?

"A linguagem não é a vida, ela dá ordem à vida, a vida não fala, ela escuta e guarda" (DELEUZE; GUATTARI, 2011, p. 13).

Paradoxalmente, a aprendizagem, que de um certo modo é morte, vem com um aprender que é vida.

Da transgressão: erro e besteira. $\mathrm{O}$ erro como aquilo que é capaz de evidenciar uma falsa representação. A besteira como aquilo que não suporta o imperativo; ao desvio: duas estruturas do pensamento.

Como seria uma matemática que se presentificasse em cores? O que decorre dessa materialidade? Uma aprendizagem.

Aprender diz respeito essencialmente aos signos. Os signos são objeto de um aprendizado temporal, não de um saber abstrato. Aprender é, de início, considerar uma matéria, um objeto, um ser, como se emitissem signos a serem decifrados, interpretados (DELEUZE, 2010, p. 4).

Um deslocar na compreensão do erro e da besteira, um desvio que produz uma aprendizagem. Um desvio que evidencia uma aprendizagem que suspeita de seus modos de transmissão. Kastrup (2007, p. 224) propõe uma noção de aprendizagem como coengendramento de si e do mundo. Para a autora, a aprendizagem deixa de pressupor sujeito e objeto como anteriores e passa a ser uma possibilidade para fazer a "cognição se diferenciar permanentemente de si mesma, fazê-la bifurcar".

$\mathrm{Na}$ esteira da ruptura com esse modo de compreender a aprendizagem, traz-se uma outra perspectiva para o aprender. Aprender abre-se à dimensão do

[...] ser sensível aos signos, considerar o mundo como coisa a ser decifrada é, sem dúvida, um dom. Mas esse dom correria o risco de permanecer oculto em nós

\footnotetext{
${ }^{4}$ A recognição se define pelo exercício concordante de todas as faculdades sobre um objeto suposto como sendo o mesmo: é o mesmo objeto que pode ser visto, tocado, lembrado, imaginado, concebido... Ou, como diz Descartes do pedaço de cera, "é o mesmo que vejo, que toco, que imagino e, enfim, é o mesmo que sempre acreditei ter estado no começo". Sem dúvida, cada faculdade tem seus dados particulares, o sensível, o memorável, o imaginável, o inteligível... e seu estilo particular, seus atos particulares investindo o dado. Mas um objeto é reconhecido quando uma faculdade o visa como idêntico ao de uma outra ou, antes, quando todas as faculdades em conjunto referem seu dado e referem a si mesmas a uma forma de identidade do objeto (DELEUZE, 2006, p. 131).
} 
mesmos se não tivéssemos os encontros necessários; e esses encontros ficariam sem efeito se não conseguíssemos vencer certas crenças (DELEUZE, 2010, p. 27).

Nesse sentido, Deleuze (2006, p. 159) afirma:

\begin{abstract}
Nunca se sabe de antemão como alguém vai aprender - que amores tornam alguém bom em Latim, por meio de que encontros se é filósofo, em que dicionários se aprende a pensar. Os limites das faculdades se encaixam uns nos outros sob a forma quebrada daquilo que traz e transmite a diferença. Não há método para encontrar tesouros nem para aprender, mas um violento adestramento, uma cultura ou paideia que percorre inteiramente todo o indivíduo (um albino em que nasce o ato de sentir na sensibilidade, um afásico em que nasce a fala na linguagem, um acéfalo em que nasce pensar no pensamento). O método é o meio de saber quem regula a colaboração de todas as faculdades.
\end{abstract}

O que está em jogo é uma aprendizagem que acione e reivindique outro aspecto da “palavra de ordem, a fuga e não a morte” (DELEUZE; GUATTARI, 2011, p. 60).

Para entrar nesse movimento de linhas de fuga, uma formação de professores que ensinarão matemática pode produzir um furo na estrutura funcional do que se entende por aprender e ensinar matemática, na noção de erro e de besteira, na medida em que coloca em questões e problematiza formas canônicas de um pensar matemático, abrindo para pensar a aprendizagem perspectivada pela noção de aprendizagem inventiva ${ }^{5}$.

"A aprendizagem inventiva inclui a experiência de problematização, que se revela através de breakdowns, que constituem rupturas no fluxo cognitivo habitual" (KASTRUP, 2004, p. 8).

Uma aprendizagem inventiva, na experiência de uma sala de aula de professores que ensinarão matemática, tem relação com uma potência de se colocar problemas ${ }^{6}$, não como busca de respostas prontas, mas uma possibilidade de colocar o próprio pensar a pensar na educação matemática, disparando modos potentes de se produzir no e com o mundo.

Para a autora, esse aprendizado está associado à "suspensão da atitude natural, que é aquela da atitude recognitiva e da consciência intencional” (KASTRUP, 2004, p. 13), delineando, assim, o seu diferencial em relação a outros modos de compreensão da aprendizagem pautados no reconhecimento.

Essa perspectiva de aprendizagem, uma aprendizagem inventiva, que vá além de uma transmissão de conhecimento relacionada a pretensas formas já instituídas de como pensar e

\footnotetext{
${ }^{5}$ A noção de aprendizagem inventiva é utilizada como próxima de Kastrup (2001). Essa noção não inclui apenas invenção de problemas e revela-se, também, como invenção de mundo. Trata-se de compreender a aprendizagem como potência de invenção e de novidade.

${ }^{6}$ Problema na perspectiva de aprendizagem inventiva "não é uma forma percebida, não é uma imagem, é antes uma potência de chegar a imagens, mas sem ter em princípio, sua forma exterior e aparente" (KASTRUP, 2007, p. 117).
} 
aprender, exige abandono do território, empreende uma impossibilidade ao pensar espontâneo e a serviço de um reconhecimento.

Reconhecemos as coisas sem jamais as conhecermos. Confundimos o significado do signo com o ser ou o objeto que ele designa. Passamos ao largo dos mais belos encontros, nos esquivando dos imperativos que eles emanam: ao aprofundamento dos encontros, preferimos a facilidade das recognições [...] (DELEUZE, 2010, p. 27).

O pensamento não é pensado por uma boa vontade, ele é violentado por encontros. “[...] o que nos violenta é mais rico do que todos os frutos de nossa boa vontade ou de nosso trabalho aplicado; e mais importante do que o pensamento é 'aquilo que faz pensar"' (DELEUZE, 2010, p. 30).

Quais efeitos teria essa noção de aprendizagem inventiva na formação de professores que ensinarão matemática, que reivindiquem outras palavras em sala de matemática? Por um lado, essa outra perspectiva de aprendizagem incide sobre a vida na medida em que compreende a aprendizagem como processualidade do vivido, naquilo em que alguém se torna. Os efeitos dessa dimensão de aprendizagem "não podem ser concebidos como movimento que percorre uma linha estratificada, indo de um ponto a outro, a partir de um único ponto de vista dado como correto, mas sim por movimentos rizomáticos de um pensamento que é afetado por modos e intensidades diferentes, produzindo caminhos diferenciados, linhas que se articulam a outras se produzindo incessantemente" (ELIAS; AXT, 2004, p. 26).

Por outro, indissociável do anterior, essa noção de aprendizagem incide sobre o pensamento, através dessas intensidades diferenciadas, das problematizações que são colocadas no vivido, das linhas que constituem os modos como alguém torna-se o que se é, violentando o pensamento, forjando caminhos inesperados e diferenciados no aprender. "Se não deixam que você fabrique suas questões, com elementos vindos de toda parte, de qualquer lugar, se as colocam a você, não tem muito o que dizer" (DELEUZE, 1998, p. 9).

Com isso, um aprender em sala de aula de matemática ocorre na processualidade do vivido, num campo invadido e composto pelo fluxo da colocação de problemas e na força que irrompe do que faz pensar: erro, besteira, seja ela de matemática ou qualquer outra. É no entre da tensão que se dá a suspensão das pretensas formas padronizadas, que se incide a suspeita da infalibilidade de uma maneira de pensar que vá garantir uma aprendizagem.

\section{Referências}

CLARETO, S. M.; SILVA, A. A. Quanto de Inusitado Guarda uma Sala de Aula de Matemática? aprendizagens e erro. Bolema, Rio Claro, v. 30, n. 56, p. 926 - 938, dez. 2016. Disponível em: 
<http://www.scielo.br/pdf/bolema/v30n56/1980-4415-bolema-30-56-0926.pdf>. Acesso em: 05 jan. 2017.

DELEUZE, G. Proust e os Signos. 2. ed. Tradução de A. C. Piquet; R. Machado. Rio de Janeiro: Forense Universitária, 2010. p. 5-175.

Diferença e repetição. 2. ed. Trad. Luiz B. L. Orlandi, Roberto Machado. Rio de Janeiro: Graal, 2006. p. 129-270.

. Lógica do Sentido (1969). 4. ed. Tradução de L. R.. S. Fortes. São Paulo: Perspectiva. 1998. p. 1-273. Séries $1^{\mathrm{a}}, 2^{\mathrm{a}}, 3^{\mathrm{a}}, 4^{\mathrm{a}}, 5^{\mathrm{a}}, 6^{\mathrm{a}}, 10^{\mathrm{a}}, 15^{\mathrm{a}}, 21^{\mathrm{a}}, 31^{\mathrm{a}}$ e o apêndice: "Platão e o simulacro".

; GUATTARI, F. Mil Platôs: capitalismo e esquizofrenia. v. 2. Tradução de A. L. Oliveira e L. C. Leão. São Paulo: Ed. 34, 2011.p. 4-113.

ELIAS, C. R.; AXT, M.. Quando aprender é perder tempo.... Compondo relações entre linguagem, apredizagem e sentido. Psicologia \& Sociedade, Belo Horizonte, v. 16, n.3, p. 17-28, set./dec. 2004 . Disponível em: <http://www.scielo.br/scielo.php?script=sci_arttext\&pid=S0102-

71822004000300003>. Acesso em: 12 jan. 2016.

GALLO, S.; SOUZA, R. M. de. Entre maioridades e minoridades: língua, cultura e política no plural. Políticas Educativas, Campinas, v.1, n.1. p. 124-140, out. 2007.

GUARIENTI, L. B. O. A potência do espaço como desvio no aprender dos corpos deambulantes. Geograficidade, Niterói, v. 2, Número Especial. p. 202-217, 2012.

KAFKA, F. O Veredicto. Tradução de M. Backes. 2 ed. Porto Alegre: L\&PM, 2014. p. 107-127.

KASTRUP, V. A invenção de si e do mundo: uma introdução do tempo e do coletivo no estudo da cognição. 1. ed. Belo Horizonte: Autêntica, 2007. p. 11-253.

A aprendizagem da atenção na cognição inventiva. Psicologia \& Sociedade, Belo Horizonte, v. 16, n. 3, p. 7-16, set/dez. 2004. Disponível em: <http://www.scielo.br/pdf/psoc/v16n3/a02v16n3.pdf>. Acesso em: 20 maio 2016.

. Aprendizagem, arte e invenção. Psicologia em Estudo: Educação \& Sociedade, Maringá, v. 6, n. 1, p. 17-27, jan./jun. 2001. Disponível em: <ttp://www.scielo.br/scielo.php?pid=S1413$73722001000100003 \&$ script=sci_abstract $\&$ tlng $=$ pt $>$. Acesso em: 20 maio 2016.

LISPECTOR. C. Água Viva. 1. ed. Rio de Janeiro: Rocco, 1998. p. 9-95

NIETZSCHE, Friedrich. Humano demasiado Humano. Tradução de P. C. de Souza. 11. ed. São Paulo: Companhia das Letras, 2015. p. 15-273.

Genealogia da Moral: uma polêmica. Tradução de P. C. de Souza7. ed. São Paulo:

Companhia das Letras, 1998. p. 7-149.

Submetido em Junho de 2016. Aprovado em Novembro de 2016. 